\title{
The Relationship between Relaxation Techniques and Sport Performance
}

\author{
Vincent A. Parnabas ${ }^{1, *}$, Yahaya Mahamood ${ }^{2}$, Julinamary Parnabas ${ }^{3}$, Nagoor Meera Abdullah ${ }^{1}$ \\ ${ }^{1}$ Faculty of Sport Science and Recreation, Universiti Teknologi MARA (UiTM), Shah Alam, 40450 Selangor, Malaysia \\ ${ }^{2}$ Faculty of College of Art and Science, University Utara Malaysia (UUM), Malaysia \\ ${ }^{3}$ Institut Pendidikan Guru, Kampus Darulaman, Jitra, Kedah, Malaysia \\ *Corresponding Author: vincent@salam.uitm.edu.my
}

Copyright $@ 2014$ Horizon Research Publishing All rights reserved.

\begin{abstract}
Anxiety, as negative emotion, affect perceptions in sports competitions, where a large majority of athletes consider anxiety to be debilitative towards performance, which may result in decreases in performance. Several researches on anxiety among athletes indicated that athletes take drugs to combat anxiety and enhance performance. There are many researches indicating that relaxation techniques benefits athletes by enhancing self-confidence, concentration, performance, reducing anxiety and stress, blood pressure as well as muscle tense. The aim of this research was to find the correlation between different kinds of relaxation techniques and sports performance. The sample consisted of 122 athletes. The sample was drawn from athletes who competed in Sports between University (MASUM). The Questionnaire of Imagery, The Questionnaire of Meditation, The Questionnaire of Progressive Muscle Relaxation and The Questionnaire of Techniques of Breathing, was used in this study. Besides that, Sports Performance Questionnaire also has been used in this study to correlate the relationship between the relaxation techniques and performance of athletes. The result showed that there are positive correlation between imagery and sports performance, meditation and sports performance, progressive muscle relaxation and sports performance, breathing techniques and sports performance. Sport psychologist and coaches should use these findings to practice various kinds of relaxation techniques on athletes. Practicing relaxation techniques can reduce the number of athletes taking drugs to reduce anxiety and enhance performance. For sport industry, relaxation techniques product can be sold through the form of CDs, VCDs, DVDs and audio.
\end{abstract}

Keywords Anxiety, Sport Performance, Relaxation Techniques

\section{Introduction}

Sports psychologists have long believed that high levels of anxiety during competitions are harmful, worsening performance and even leading to dropouts (Hanin, 2000). Researchers have reported that over 50 percent of consultations among athletes at Olympic Games or sports events were related to stress or anxiety problems (Murphy, 1988). Anxiety, as a negative emotion, affects perception in sports competitions, where a large majority of athletes consider anxiety to be debilitative towards performance, which may result in decreases in performance (Raglin \& Hanin, 2000; Weinberg \& Gould, 2011). Anxiety consists of two subcomponents: cognitive and somatic anxiety, which influence performance (Jarvis, 2002; Martens, R., Vealey \& Burton, 1990). Cognitive is the mental component, which is characterized by negative expectations about success or self-evaluation, negative self-talk, worries about performance, images of failure, inability to concentrate and disrupted attention (Jarvis, 2002; Martens, Vealey \& Burton, 1990). The somatic is the physiological element, which related to autonomic arousals, negative symptoms such as feelings of nervousness, high blood pressure, dry throat, muscular tension, rapid heart rate, sweaty palms and butterflies in the stomach (Jarvis, 2002; Jones, 2000; Martens, Vealey \& Burton, 1990).

Several researches on anxiety among athletes showed that athletes took drugs to combat with anxiety and enhance performance. The relatively widespread use of drugs to enhance performance dates back at least to the Olympic of the 1960's, although broad public awareness of such drugs use seems relatively recent (Simon, 2007). It is estimated that six out of 10 athletes at the games are taking banned substances to reduce anxiety and enhance performance (Wilson, 2012). Even though drugs consumption benefits the athletes in terms of reducing the levels of anxiety and enhances sports performance, but it is a cheating, foul play, unfair, dishonest and unsportsmanlike actions. However, significance number of research done on relaxation techniques showed that it has the tendency to reduce anxiety and enhance performance. Since lack of knowledge, it may not reach many athletes and hence, athletes took drugs to 
enhance their performance. Therefore, future sports should focus on applying relaxation techniques to reduce the number of athletes taking drugs in order to combat anxiety and enhance performance. Sports industry can sell the relaxation techniques in the form of CDs, VCDs, DVDs or audio in different languages.

A significance amount of research has been conducted on competitive anxiety on sports (Martens, Vealey \& Burton, 1990) and the relaxation techniques (Humara, 2001; Martens, Vealey \& Burton, 1990; Richards, 2004). Research has indicated that most successful athletes used relaxation techniques compared to less successful athletes (Gould, Eklund \& Jackson, 1993; Orlick \&Partington, 1988). Many researches indicated that relaxation techniques benefits athletes by enhancing self-confidence, concentration, performance, reducing anxiety and stress, blood pressure besides muscle tense (Pragman, 1998; Vincent \& Yahaya, 2012; Weinberg \& Gould, 2011). Since relaxation techniques benefits athletes in variety of ways and enhance performance, future sports industries should focus on developing relaxation techniques.

One of the most popular methods of relaxation is Progressive Muscle Relaxation. In using this technique, an athlete tense up a group of muscles so that they are as tight as possible, and holds them in a state of extreme tension for a few seconds (Ampofo-Boateng, 2009). The muscles are then progressively relaxed to their previous conditions.

Breathing control, involving deep breathing is another relaxation technique that is used to help athletes deal with anxiety. Deep breathing is an effective method of relaxation. There are 3 techniques of breathing for reducing the level of anxiety, known as The Measured Breath, The Bumble Bee Breath and Belly Breathing (Anxiety Breathing Techniques You Can Practice Anywhere. 2013).

Imagery, known as mental rehearsal, mental visualization or mental practice, helps athletes to reduce anxiety and improve performance by activating the muscles (Bull, 2000; Cox, 2011; Cox, Qiu \& Liu, 1993). Imagery in its simplest form, involves an athlete imagining a scene, place of even that he or she sees as peaceful, restful, beautiful and bringing happiness. According to (Feltz \& Lirgg. 2007) imagery is the most common technique to improve performance among athletes in competitive situation. The senses for imagery may include, but not limited to:

i. Sounds of running water and rivers.

ii. That resemble green space like natural or semi natural habitats, rivers, canals, parks, gardens, street trees, parks, golf courses, sports fields, mountain view, sounds of running water, grass, flowers, the scene of cool mountain water, the breath of fresh air and so on.

The practice of meditation is associated with a passive attitude and decreased muscle tone, able to reduce anxiety, insomnia and psychosomatic diseases and enhance energy, intelligence, creativity and health (Christchurch; Cox, 2011; Hackfort \& Schwenkmezger, 1993).Even though the benefits of meditation are many, since lack of knowledge many athletes not practicing meditation. Future industry on sports market should focus on producing products based on meditation techniques, so that many athletes can benefits using these meditations.

In an effort to achieve a psychological state conductive for successful sports performance, athletes are using relaxation techniques that are still new to the sports world.

\section{Aim of the Study}

The aim of this research was to find the correlation between different kinds of relaxation techniques and sports performance.

\section{Method}

The sample consisted of 122 athletes. The sample was drawn from athletes who competed in Sports between Universities (MASUM). The Questionnaire of Imagery, The Questionnaire of Meditation, The Questionnaire of Progressive Muscle Relaxation and The Questionnaire of Techniques of Breathing, was used in this study. Besides that, Sports Performance Questionnaire also has been used in this study to correlate the relationship between the relaxation techniques and performance of athletes.

\section{Result}

\subsection{Cronbach Reliability Coefficients}

In this study, Cronbach alpha were found ranging from .81 to .87 . Coefficients of .70 and above were considered reliable, therefore included in the interpretation of the data (Table 1).

Table 1. Cronbach Reliability Coefficients

\begin{tabular}{|c|c|}
\hline Relaxation Techniques Questionnaires & $\begin{array}{c}\text { Cronbach's Alpha } \\
(\mathrm{n}=122)\end{array}$ \\
\hline The Questionnaire of Imagery & .8271 \\
\hline The Questionnaire of Meditation, & .8713 \\
\hline $\begin{array}{c}\text { The Questionnaire of Progressive Muscle } \\
\text { Relaxation }\end{array}$ & .8590 \\
\hline $\begin{array}{c}\text { The Questionnaire of Techniques of } \\
\text { Breathing }\end{array}$ & .8123 \\
\hline Sports Performance Questionnaire & .8121 \\
\hline
\end{tabular}

\subsection{Profile of the Respondents}

Frequency, Percentage, mean and standard deviation are presented in Table 2, which shows the overall results of the respondents' profile. The profile of the respondents described the ethnics, gender, age and level of sport performance. There are 71 male and 51 female athletes participated in this study.

Based on the ethnic, the majority of athletes belong to 
Malays (55.74\%) since they are the majority race in Malaysia. The second largest ethnic in Malaysia are Chinese. There are $25.41 \%$ athletes from Chinese ethnic. Indians are the lowest ethnic in Malaysia. There are $18.85 \%$ athletes from Indian ethnic.

The mean age for overall respondents was 22.22 years old. The age of male varied from 19 to 27 years, where the mean age was 22.17 years old. The age of females ranged from the minimum of 18 to the maximum of 26 years old. The mean age for female respondents was 21.70 years old.

The variable "level of sport performance" is gathered through the studies. Based on the level of performance, the majority of the respondents obtain the highest performance in sport, national $(72.13 \%)$. followed by state $(9.02 \%)$, district $(9.83 \%)$ and university level $(9.02 \%)$,

Table 2. Profile of the respondents

\begin{tabular}{|c|c|c|c|c|}
\hline Variables & Frequency & Percentage & Mean & SD \\
\hline Ethnics & & & & \\
\hline Malay & 68 & 55.74 & & \\
\hline Chinese & 31 & 25.41 & & \\
\hline Indian & 23 & 18.85 & & \\
\hline Gender & & & & \\
\hline Male & 71 & 58.20 & & \\
\hline Female & 51 & 41.80 & & \\
\hline Age & & & & \\
\hline Male & & & 22.17 & 2.31 \\
\hline Female & & & 21.70 & 1.89 \\
\hline Overall & & & 22.22 & 1.97 \\
\hline $\begin{array}{c}\text { Level of } \\
\text { Performance }\end{array}$ & & & & \\
\hline National & 88 & 72.13 & & \\
\hline State & 11 & 9.02 & & \\
\hline District & 12 & 9.83 & & \\
\hline University & 11 & 9.02 & & \\
\hline
\end{tabular}

\subsection{Imagery and Sports Performance}

The correlation coefficient of 0.097 was noted between the usage of imagery and sports performance in the evaluation of 122 athletes, which is significantly $(\mathrm{P}<.01)$. In other words, the relationship existing between these variables is statistically significant (Table 3 ).

Table 3. The Relationship between The Usage of Imagery and Sports Performance among Athletes

\begin{tabular}{|c|c|}
\hline Subject & Sports Performance \\
\hline The Usage of Imagery & $0.097 * *$ \\
\hline$* * \mathrm{p}<.01$
\end{tabular}

\subsection{Meditation and Sports Performance}

The correlation coefficient of 0.091 was noted between the usage of meditation and sports performance in the evaluation of 122 athletes, which is significantly $(\mathrm{P}<.01)$. In other words, the relationship existing between these variables is statistically significant (Table 4).

Table 4. The Relationship between The Usage of Meditation and Sports Performance among Athletes

\begin{tabular}{|c|c|}
\hline Subject & Sports Performance \\
\hline The Usage of Meditation & $0.091^{* *}$ \\
\hline
\end{tabular}

$* * \mathrm{p}<.01$

\subsection{Progressive Muscle Relaxation and Sports Performance}

The correlation coefficient of 0.078 was noted between the usage of Imagery and sports performance in the evaluation of 122 athletes, which is significantly $(\mathrm{P}<.01)$. In other words, the relationship existing between these variables is statistically significant (Table 5).

Table 5. The Relationship between The Usage of Progressive Muscle Relaxation and Sports Performance among Athletes

\begin{tabular}{|c|c|}
\hline Subject & Sports Performance \\
\hline $\begin{array}{c}\text { The Usage of Progressive Muscle } \\
\text { Relaxation }\end{array}$ & $0.078^{* *}$ \\
\hline$* * \mathrm{p}<.01$
\end{tabular}

\subsection{Breathing Techniques and Sports Performance}

The correlation coefficient of 0.098 was noted between the usage of breathing techniques and sports performance in the evaluation of 122 athletes, which is significantly $(\mathrm{P}<.01)$. In other words, the relationship existing between these variables is statistically significant (Table 6).

Table 6. The Relationship between The Usage of Breathing Techniques and Sports Performance among Athletes

\begin{tabular}{|l|c|}
\hline Subject & Sports Performance \\
\hline The Usage of Breathing Tehniques & $0.091^{* *}$ \\
\hline
\end{tabular}

$* * \mathrm{p}<.01$

\section{Discussion}

\subsection{Imagery and Sports Performance}

The result showed that there is positive correlation between the usage of imagery and sports performance. In other words, the higher the usage of imagery, the higher the level of sports performance. As noted earlier, there is reasonable number of researches managed to prove that imagery can enhance sports performance. The product of imagery, in the form of CDs, VCDs, DVDs and audio can guide the athletes to experience an effective imagery.

\subsection{Meditation and Sports Performance}


The result showed that there a positive correlation between the usage of meditation and sports performance. In other words, the higher the usage of meditation, the higher the level of sports performance. The practices of meditation, not only relax the mind and body, but also enhance the concentration. These help athletes to increase the level of performance in sports. There are many kinds of meditation such as Chakra yoga, Rinzai Zen, Mudra yoga, Sufism, Tai Chi, Zen meditation and Soto Zen, which can be marketable in sports industry.

\subsection{Breathing Techniques and Sports Performance}

The result showed that there a positive correlation between the usage of breathing techniques and sports performance. In other words, the higher the usage of breathing techniques, the higher the level of sports performance. Many researches had proved that breathing techniques benefit not only athletes involved in individual sports but also in team sports (Eggleston, College \& Smith, 2007; Miller, 2000). Even though breathing method is the simplest technique of relaxation but not many athletes practicing it due to lack of knowledge. Sports industries should produce different kind of product that facilitates breathing techniques in CDs, DVDs or in audio form to reach athletes.

\subsection{Progressive Muscle Relaxation and Sports Performance}

The result showed that there is a positive correlation between the usage of progressive muscle relaxation and sports performance. In other words, the higher the usage of the progressive muscle relaxation, the higher the level of sports performance increases. Progressive muscle relaxation technique is a powerful technique to reduce the oxygen metabolism, respiration, blood pressure, muscle tense and negative thoughts (Anshel, 2003; Keable, 1989; Nelson-Jones, 2003).

\section{Conclusion and Recommendation}

The result showed that there is positive correlation between imagery and sports performance, meditation and sports performance, progressive muscle relaxation and sports performance, breathing techniques and sports performance. This showed that relaxation techniques have the tendency to enhance performance by reducing stress and anxiety and enhance sports performance. Sports psychologist and coach should use these findings to apply various kinds of relaxation on athletes. For sport industry, relaxation techniques product can be sold through the form of CDs, VCDs, DVDs and audio. Introducing relaxation techniques in the sports market can reduce the number of athletes taking drugs to reduce anxiety and enhance performance.

\section{REFERENCES}

[1] Anshel, M.H. 2003.Sport psychology: from theory to practice.New York: Benjamin Cummings.

[2] Ampofo-Boateng, K. 2009.Understanding Sport Psychology. Shah Alam, Malaysia: UPENA.

[3] Anxiety Breathing Techniques You Can Practice Anywhere. 2013.(http://www.anxietyslayer.com/journal/3-anxiety-breat hing-techniques-you-can-practice-anywhere.html).

[4] Bull, S.J. 2000. Sport Psychology: A self-help guide. Ramsbury, Marlborough: Crowood.

[5] Christchurch. 2002. Transcendental Meditation: An investment for health, energy, wealth, happiness and success. (http://www.About Transcendental Meditation.htm.).

[6] Cox, R. H. 2011.Sport Psychology, concepts and applications. New York: McGraw-Hill.

[7] Cox, R.H., Qiu, Y. \& Liu, Z 1993.Overview of sport psychology.In R.N.Singer, M. Murphey and L.K. Tennant, Handbook of research on sport psychology. New York: Macmillan.

[8] Eggleston, T., College, M. \& Smith, G. 2007. Going for the Gold: Using Sports Psychology to Improve Teaching and Learning. Psychological Science $20 \quad$ (3). (http://www.psychologicalscience.org/observer/getArticle.cf $\mathrm{m}$ ?id=2144).

[9] Feltz. D. L. \& Lirgg. C. D. 2007.Self-efficacy beliefs of athletes, teams and coaches.In R.N. Singer., H.A. Hausenblaus., and C.M. Janelle (EDS).Hand Book of Sport Psychology. New York: Wiley.

[10] Gould, D.,Eklund, R., \& Jackson, S. 1993. Coping strategies used by U.S Olympic Wrestlers. Research Quarterly for Exercise and Sport 64, 83-93.

[11] Hackfort, D. \& Schwenkmezger, P. 1993. Anxiety. In R.N. Singer, M. Murphey and L.K. Tennant, Handbook of research on sport psychology. New York: Macmillan.

[12] Hanin, Y. L. 2000. Emotions in sport. Champaign, IL: Human Kinetics.

[13] Humara, M. 2001. The relationship between anxiety and performance: A Cognitive-behavioral perspective. Athletic Insight 1(2): The Online Journal of Sport Psychology.

[14] Keable, D. 1989. The management of anxiety: A manual for therapists. London: Churchill Livingstone.

[15] Jarvis, M. 2002. Sport Psychology. New York: Routledge.

[16] Jones, G. 2000. Stress and anxiety. In S.J. Bull, Sport Psychology:A self-help Guide. Ramsbury, Marlborough: Crowood.

[17] Martens, R., Vealey, R.S., \& Burton, D. 1990. Competitive Anxiety in Sport. Champaign, Illinois: Human Kinetics.

[18] Miller, B. 2000. Mental preparation for competition. In S.J. Bull, Sport Psychology: A self-help guide.Ramsbury, Marlborough: Crowood. 
[19] Murphy, S. M. 1988. The on-site provision of sport psychology services at the 1987 U. S Olympic Festival. The Sport Psychologist 2, 105-130.

[20] Nelson-Jones, R. 2003.Basic counseling skills: A helper's manual. London: Sage.

[21] Simon, R. L. 2007. Good competition and Drug-Enhanced Performance. In W. J. Morgan, Ethics in Sport. Champaign, IL: Human Kinetics.

[22] Orlick, T., \&Partington, J. 1988. Mental links to excellence. The Sport Psychologist2, 105-130.

[23] Pederson, P.M., Parks, J. B., Quarterman, J.\&Thibayult, L. 2011. Contemporary Sport Management. United States: Human Kinetics.

[24] Pragman, D. 1998. Understanding sport psychology. New Jersey: Prentice-Hall.

[25] Raglin, J.S. \&Hanin, Y.L. 2000.Competitive anxiety. In Yuri, L.H., Emotions in Sport. Champaign, IL: Human Kinetics.
[26] Richards, H. 2004. Coping in sport.InD.Lavallee, J.Thatcher, \& M.V. Jones(Eds.), Coping and emotion in sport. New York: Nova Science Publishers, Inc.

[27] Taylor, J. 1996. Intensity regulation and athletic performance.In J.L. Van Raalte and B.W. Brewer (Eds.), Exploring sport and exercise psychology. Washington, DC: American Psychological Association.

[28] Vincent, P \& Yahaya, M. 2012.Anxiety and Imagery of Green Space among Athletes.British Journal of Arts and Social Sciences, 4(1), 67-72.

[29] Weinberg, R.S. \& Gould, D., 2011. Foundations of Sport and Exercise Psychology. Champaign, IL: Human Kinetics.

[30] Wilson, N. 2012 (9 August 2012). Games drugs slur: Chambers' doping guru claims 60 per cent of athletes are cheating. Mail on line Olympic. (http://www.dailymail.co.uk/sport/olympics/article-2185691/ London-2012-Olympics-60-cent-athletes-using-drugs-claims -disgraced-supplier.html). 